\title{
Outcomes of Primary Percutaneous Coronary Intervention (PCI) in NICVD, Dhaka,Bangladesh- Our Initial Experiences
}

\author{
MIR JAMALUDDIN ${ }^{1}$, IBRAHIM KHALIL ${ }^{1}$, KAJAL KUMAR KARMAKAR ${ }^{1}$, HUMAYUN KABIR $^{1}$ \\ RAKIBUL ISLAM LITU ${ }^{2}$, BAZLUR RASHID ${ }^{5}$, A.H.K CHOWDHURY ${ }^{1}$, A.A.S MAJUMDER ${ }^{1}$, ABUL KHAIR ${ }^{1}$, \\ ZAHID HASAN $^{1}$, SHAHIN KABIR ${ }^{1}$, KHQ ISLAM ${ }^{1}$, AMAL KUMAR CHOWDHURY ${ }^{1}$, G.K. SHAHA ${ }^{1}$, MAHBOOB ALI ${ }^{1}$, \\ AFZALUR RAHMAN ${ }^{1}$, ABDUL KADER AKANDA ${ }^{1}$, MAMUNUR RASHID ${ }^{1}$ \\ ${ }^{1}$ Department of Cardiology, National Institute of Cardiovascular Disease (NICVD), Dhaka, ${ }^{2}$ Department of Cardiology, \\ Uttara Adhunik Medical College, Dhaka
}

Address of Correspondence: Dr. Mir Jamaluddin, Professor of Cardiology, National Institute of Cardiovascular Disease (NICVD), Dhaka

\begin{abstract}
The aim of the study is to determine the out comes of primary percutaneous coronary intervention (PCI) in patients with acute myocardial infarction in NICVD the only government cardiac hospital of Bangladesh where resources are very limited. Total 73 (male 70, female 3) patients were enrolled in this study who were brought in to our hospital with STEMI between August 2010 to October 2013. Average age was 55.6 \pm 11.78 . Primary PCI was performed after transferring patient from Emergency Department to cardiac catheterization laboratory. Cardiovascular risk factors among the studied population were Diabetes mellitus, Hypertension, Smoking, Dyslipidemia and Positive family history for IHD. Primary PCI either with Bare Metal Stent (BMS) or Drug Eluting Stent (DES) were performed in total 42 LAD lesions, 28 RCA lesions and 3 LCX lesions. BMS used were $87.7 \%$, DES used were $12.3 \%$. The procedural success was $95.8 \%$.Four patients (5.4\%) died during hospital stay. Out of four patients who died, one had cardiogenic shock. No mortality was observed in the 30 days follow up from discharge, while other complications like unstable angina and congestive heart failure were $5.7 \%$ and $4.3 \%$ respectively. Our findings suggest favorable outcomes, matching the international data which was achieved in our patients with primary PCI in the management of STEMI despite all the limitations. Primary PCI as a preferred method of reperfusion strategy needs to be practiced more often in our part of world.
\end{abstract}

Keywords- Primary PCI, STEMI

Introduction:

Cardiovascular diseases including myocardial infarction (MI) and heart failure, remains the leading causes of death worldwide. Acute MI results mostly from acute thrombotic occlusion of an epicardial coronary artery, typically after disruption or erosion of an atherosclerotic plaque and exposure of thrombogenic material (Plaque lipid content, collagen and sub endothelial extracellular matrix) to circulating blood. The aim of acute treatment of ST elevation MI (STEMI) is restoration of myocardial perfusion by recanalization of the occluded vessel. Early reperfusion is associated with better out comes. Thrombolytic therapy and primary percutaneous coronary intervention (PCI) are used as reperfusion strategies. Several randomized trials and meta analyses have shown that primary angioplasty is superior to thrombolysis in terms of death, reinfarction and stroke ${ }^{1}$. Primary PCI is performed if a skilled interventional cardiologist and catheterization laboratory with surgical back up are available and if the procedure can be performed preferably with in 90 minutes after initial medical contact with the patient $^{2}$. Few studies from India including a study by Reddy et al concluded that primary angioplasty is safe and effective with procedural success rate (99\%) and lower rates of recurrent ischemic events (5\%) ${ }^{3}$. In Bangladesh there is a single study in Apollo hospital, Dhaka done by A.Q.M Reza et al showed that primary PCI increases higher survival out come in 28(93.3\%) out of 30 patients with acute STEMI ${ }^{4}$. The aim of our study is to evaluate safety and survival out come \& benefit of primary PCI in our only tertiary care cardiac centre at government level where resources are limited. This will provide a very strong rationale to conduct such a study, so as to determine the out come of primary PCI in our population and to compare it with international data.

\section{Methods:}

Patients were randomized from the cases who presented to our emergency department (ED) with the onset of chest pain out side the hospital of any age for at least 30 minutes, 
but less than 12 hrs in duration. Total study period was between August 2010 to October 2013. Total number of patient was 73 .

Electrocardiographic criteria were associated with ST segment elevation of $\geq 2 \mathrm{~mm}$ in chest leads \& $\geq 1 \mathrm{~mm}$ in limb leads in $\geq 2$ contiguous leads. Prior to primary PCI informed written consent were taken from the patient or guardians. All these patient underwent primary PCI as mode of reperfusion through femoral route. All patient in emergency department received Aspirin 300mg, clopidogrel 600 mg as per indication. Patient underwent diagnostic angiogram followed by primary PCI of the infarct related artery.

After thrombus suction where required from the occluded site by a thrombuster sucker, balloon dilatation was done in selected cases. All culprit lesions were stented mostly with bare metal stent (BMS) and few of them by drug Eluting stent (DES). Further smoothening was done by post dilatation whenever required. IVUS was not available in our hospital. Before PCI standard heparin 10,000 units IV bolus was given. Glycoprotein (GP) llb/IIIa antagonist, Eptifibatide was used both as intra coronary bolus and I.V maintenance in all cases. Intracoronary nitrates \& adenosine use were at the judgement of the operator. Stent size selection was primarily based on visual assessment of lesion length and vessel diameter. All patients were prescribed aspirin 75mg daily for indefinite time. Clopidogrel $75 \mathrm{mg}$ daily for a minimum of one month in case of BMS and for one year in case of DES. Post PCI all patients initially remained in coronary care unit and later shifted to coronary step down unit before discharge, Routine follow up was done after one week \& four week of discharge.

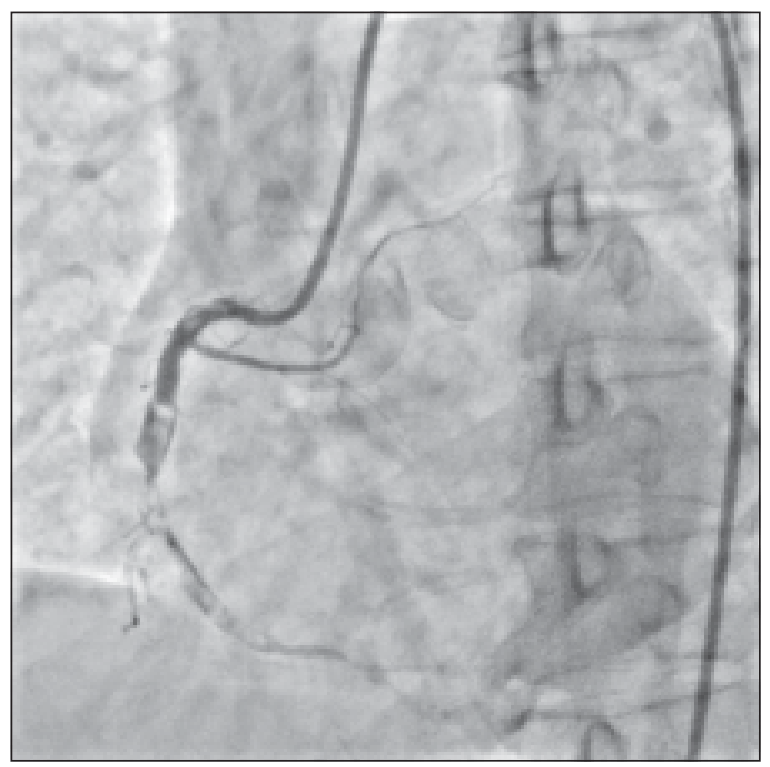

Fig.-1: Thrombus burden and critical stenosis in mid RCA in a patient before Primary PCI

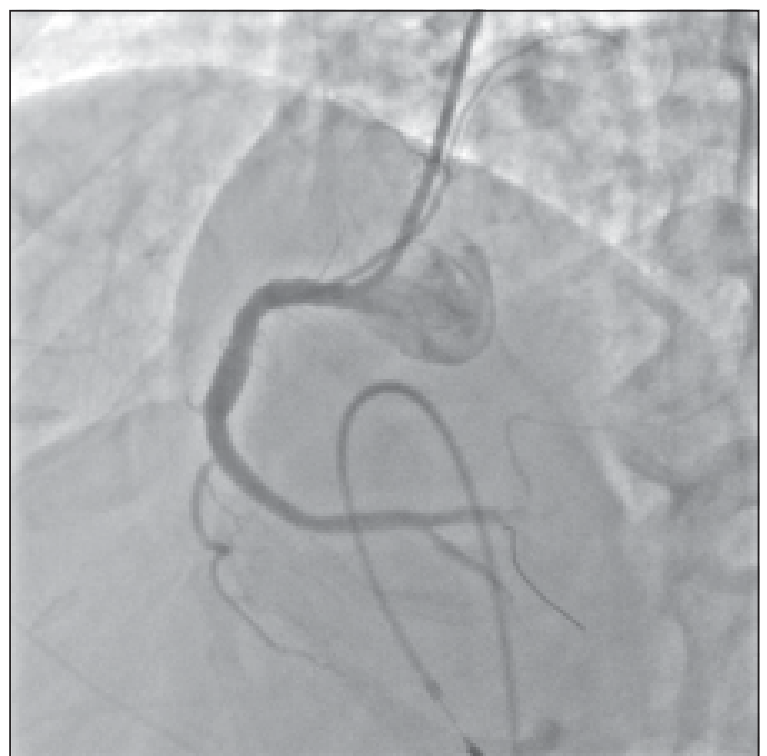

Fig.-2: After thrombus suction and stenting of RCA in same patient.

Performa was designed to collect information including age, gender, history of diabetes (defined as a fasting glucose $\geq 126 \mathrm{mg} / \mathrm{dl}$ or on treatment), hypertension BP $\geq 140 / 90 \mathrm{~mm} \mathrm{Hg}$ or on treatment), dyslipidaemia (fasting total cholesterol $\geq 200 \mathrm{mg} / \mathrm{dl}$ or on treatment), smoking, left ventricular function (visually estimated using echocardiography), presence of cardiogenic shock (defined as systolic blood pressure $<90 \mathrm{~mm}$ or requirement of inotropes to maintain a SBP $>90 \mathrm{~mm}$ of $\mathrm{Hg}$ ) angiographic and procedural details (culprit vessel, number of diseased vessels, use of stents, GP llb/llla inhibitors, Thrombolysis in myocardial infarction (TIMI) flow were also collected. Hospital charts were reviewed for further information including need for intubation, electrocardiogram (ECG) ST-segment analysis and laboratory data including haemoglobin, serum creatinine, cardiac enzymes etc. Timing variables were computed including time to presentation which is defined as the time from symptom onset until arrival at the hospital. Door-to-balloon time was the time from arrival at the hospital until balloon inflation in cardiac catheterization laboratory.

Coronary flow in the infarct related artery was assessed visually by the operator and classified according to the TIMI grading system on a scale of 0 to 3 both before and after the PCI.

Successful PCI was defined as visually assessed $<20 \%$ residual stenosis with TIMI III distal flow. Significant groin hematoma was defined as a hematoma $>10 \mathrm{~cm}$ in diameter or requiring blood transfusion. 
The primary end point was in-hospital mortality and secondary end points included 30 days out comes from discharge including mortality, reinfarction, re-current angina, congestive heart failure.

\section{Statistical Analysis}

All the variables were entered in to the statistical package for social science software, version 14(SPSS inc) for data analysis. Descriptive statistics were computed and presented as means, standard deviations were calculated for continuous variables like age, LVEF and median for onset of pain to emergency room, door to balloon time-in minutes. Categorical variables reported in percentages for the gender, hypertension, diabetes mellitus, dyslipidemia, cardiogenic shock, LVF multivessel diseases, procedural success, mortality and thirty day out come variables like myocardial infarction, recurrent angina, congestive heart failure.

\section{Results:}

A total of 73 patients were included in this study.

Table-1

Characteristics of patients undergoing primary PCI for STEMI

\begin{tabular}{lc}
\hline $\begin{array}{l}\text { Base line demographic and clinical } \\
\text { characterizes: }\end{array}$ & $\mathrm{N}=73(\%)$ \\
\hline Mean age (years) & $55.6 \pm 11.78$ \\
Male (gender) & $70(95 \%)$ \\
Female (gender) & $3(5 \%)$ \\
Past medical history: & \\
Hypertension & $35(47.9 \%)$ \\
Diabetes mellitus & $28(38.3 \%)$ \\
Current smoker & $45(61.6 \%)$ \\
Dislipidaemia & $25(34.2 \%)$ \\
Positive family history for IHD & $20(27 \%)$ \\
Previous MI & $0-(0 \%)$ \\
Previous PCI & $1(1.3 \%)$ \\
Previous CABG & $0-(0 \%)$ \\
Previous congestive heat failure & $0-(0 \%)$ \\
Admission characteristics: & \\
Cardiogenic shock & $2(2.7 \%)$ \\
Left ventricular failure & $7(9.5 \%)$ \\
Ventricular arrythmia & $3(4.1 \%)$ \\
LV ejection fraction (Mean/SD) & $43.7 \pm 7.9 \%$ \\
Anterior MI & $42(57.5 \%)$ \\
Inferior MI & $31(42.4 \%)$ \\
Timing variables: & \\
Onset of pain to first medical & 120 minutes \\
contract time (minutes) mean & \\
Door to balloon time (minutes) mean & 110 minutes \\
\hline
\end{tabular}

Table 1 shows the demographic and clinical characteristics of the patients. The mean age was $55.6 \pm 11.2$ years. There were $95 \%$ male and $5 \%$ female patient. The distribution of cardiovascular risk factors were diabetes mellitus 38.3\%, hypertension 47\%, smoking $61.6 \%$, dyslipidamia $34 \%$, positive family history of IHD $27.3 \%$. One patient was a case of recent NSTEMI with PCI to LAD who developed subacute stent thrombosis during his hospital stay. 2 patients presented with cardiogenic shock. 3 patients had ventricular tachycardia, 7 patients had acute LVF during the admission, mean LV ejection fraction was $43.7 \% \pm 7.4 \%$. Out of 73 patients 42 patients presented with anterior MI 31 patients presented with inferior MI. The median time from onset of symptom to presentation was 120 minutes and the median door to balloon time was 110 minutes.

Table-II

Angiographic and procedural characteristics of patients undergoing primary PCI for STEMI

\begin{tabular}{lc}
\hline Culprit vessel & No of case (\%) \\
\hline Left anterior descending artery & $42(57.5 \%)$ \\
Left circumflex artery & $3(6.8 \%)$ \\
Right coronary artery & $28(38.3 \%)$ \\
Multivessel CAD & $11(15 \%)$ \\
Multivessel PCI & $2(2.7 \%)$ \\
Procedural success & $69(94.5 \%)$ \\
Use stent & $73(100 \%)$ \\
Plain old balloon angioplasty (POBA) & $0(0 \%)$ \\
Intra-Aortic Balloon Pump & $2(2.7 \%)$ \\
TIMI blood flow on angiography & \\
Before PCI & \\
0 & $51(69.8 \%)$ \\
1 & $20(27.3 \%)$ \\
2 & $2(2.7 \%)$ \\
3 & $0(0 \%)$ \\
After PCI & \\
0 & $0(0 \%)$ \\
1 & $0(0 \%)$ \\
2 & $2(2.7 \%)$ \\
3 & $71(97.2 \%)$ \\
\hline
\end{tabular}

Table-2 shows the angiographic \& procedural characteristics of patients.

Left anterior descending (LAD) artery is the most common culprit vessel, 42(57.5\%) followed by right coronary artery 28(38.3\%) and left circumplex artery 3(4.1\%). Multivessel disease (defined as $>70 \%$ stenosis in $\geq 2$ epicardial vessel) was present in 2 cases (15\%). Stent were deployed in all cases. Multivessel PCI was performed in one case. The 
average dimension of stent and their deployment pressure were as follows 19.5 $\pm 73 x 3.2 \pm 0.5 @ 16.1 \pm 4.1$ ATM in LAD, $17 \pm 5.0 \times 3.0 \pm 0.2 @ 15 \pm 1.4$ ATM in LCX and 20.7 $\pm 0.6 x 3.5 \pm 0.3 @ 14.5 \pm 2.3 A T M$ in RCA.

\section{Table-III}

Average size of stents used with inflation pressure.

\begin{tabular}{ccccc}
\hline Vessel & No(\%) & $\begin{array}{c}\text { Length } \\
(\mathrm{mm})\end{array}$ & $\begin{array}{c}\text { Diameter } \\
(\mathrm{mm})\end{array}$ & $\begin{array}{c}\text { Inflation } \\
\text { pressure } \\
(\mathrm{ATM})\end{array}$ \\
\hline LAD & $42(58.5 \%)$ & $19.5 \pm 7.3$ & $3.2 \pm 0.5$ & $16.1 \pm 4.1$ \\
LCX & $3(4 \%)$ & $17 \pm 5.0$ & $3.0 \pm 0.2$ & $15 \pm 1.4$ \\
RCA & $28(38.3 \%)$ & $20.7 \pm 0.6$ & $3.5 \pm 0.3$ & $14.5 \pm 2.3$ \\
\hline
\end{tabular}

Procedure was successful in 70 (95.8\%) patients. Two patients needed intra aortic balloon counterpulsation support. Groin hematoma occurred in two patients (2.7\%). No patient needed urgent CABG. No patient developed sub acute stent thrombosis or contrast induced nephropathy.

\section{Table-IV}

In-hospital events

\begin{tabular}{lc}
\hline Death in hospital (all patients) & $4(5.4 \%)$ \\
$\begin{array}{l}\text { Death in hospital (patient without } \\
\text { cardiogenic shock) }\end{array}$ & $3(4.2 \%)$ \\
$\begin{array}{l}\text { Death in hospital (patient with } \\
\text { cardiogenic shock) }\end{array}$ & $1(50 \%)$ \\
Groin haematoma & $2(2.7 \%)$ \\
Table death & $0(0 \%)$ \\
In hospital CABG & $0(0 \%)$ \\
Stent thrombosis & $0(0 \%)$ \\
\hline
\end{tabular}

Four patients died in hospital (5.4\%). Out of four patient who died, one had cardiogenic shock during admission post discharge 30 days out comes of the studied cohort mowed no death. Major complications during one month follow up were unstable angina in 4 patient (5.7\%). Congestive cardiac failure was seen in 3 patient (4.3\%).

\section{Discussion:}

Cardiologists had recognized the importance of early reperfusion in limiting ischemic damage to the myocardium. First benefit identified with the use of thrombolytic therapy to achieve reperfusion was primarily due to two land mark large trials: the Second International Study of infarct survival group (ISIS-2) $)^{5}$ and an Italian group (GISSI) ${ }^{6}$. Both studied the effects of intravenous streptokinase given to patients with suspected acute MI. The undoubted benefits of thrombolysis are offset by its nonspecificity for the coronary circulation resulting in risk of bleeding complication and time dependent uncertainty about the efficacy of reperfusion.

In Addition there is limited evidence of the benefit of thrombolytic therapy in a number of high-risk groups including older patients and in the context of cardiogenic shock $^{7}$. PCI has potential benefits of specific and confirmed recanalization of the culprit vessel as well as knowledge of the detailed coronary anatomy. Clinical trials comparing the efficacy of thrombolysis and primary angioplasty have concluded that superior outcomes can be obtained with an invasive approach. A meta-analysis by keeley and colleagues demonstrated that Primary PCI was better than thrombolytic therapy at reducing overall short-term death $(p=0.0002)$, non-fatal reinfarction $(p<0.0001)$, stroke $(\mathrm{p}=0.0004)$ and the combined endpoint of death, non-fatal reinfarction, and stroke $(\mathrm{p}<0.0001)^{8}$.

A more recent evaluation of patients recruited into the PRAGUE-2 Study found that, at 5 years after the procedure, the incidence of reinfarction, revascularization and death from all causes was considerably reduced in those patients randomized to the PCI arm compared to thrombolytic arm with p value of $0.009,<0.001$ and 0.06 respectively ${ }^{9}$. The possible risks associated with primary PCI includes bleeding, procedure related immediate complications and radiographic contrast-related acute renal failure ${ }^{10}$.

As angioplasty offers reduced rates of complications, patients are discharged earlier and are less likely to be readmitted with a related cardiac event. Hospital costs are therefore considerably reduced in patients receiving PCI accounting for the reduced cost after one year ${ }^{11}$.

Our study shows an excellent procedural success rate (95.8\%) with an excellent over all in hospital survival rate (94.5\%). Out of 73 patients 71 patients presented without features of cardiogenic shock and 2 patients presented with features of cardiogenic shock. 3 patients out of 71 who presented without features of cardiogenic shock died (4.2\%), which is comparable to international data which showed in hospital mortality of $5.2 \%$ in second national registry of myocardial infarction (NRM-12) ${ }^{12}$ and 3\% in ASSENT 4 trial $^{13}$. In our study two patient had cardiogenic shock. Out of them one died (50\%) which is again comparable to international data which showed higher mortality in patient with cardiogenic shock i.e $46.4 \%$ in shock registry ${ }^{14}$ and $59.1 \%$ in American college of cardiology- National Cardio Vascular data registry (ACC-NCDR) ${ }^{15}$. Study from India by Reddy at $\mathrm{al}^{3}$ and from Pakistan by Ayaz Hussain et al ${ }^{16}$ showed an in hospital mortality of $2.2 \%$ and $1 \%$ respectively 
in non-cardiogenic shock group. In our country previous single study conducted by AQM Reza ${ }^{4}$ had shown inhospital survival rate $93.8 \%$ which is also comparable to our present study where survival rate is $94.5 \%$. In our study we used mainly bare metal stent (BMS). Drug Eluting stent (DES) was used in 9 cases. Although the use of DES and its rate on acute stent thrombosis is still debatable, majority are using BMS. Our patient treated with DES has no documented acute stent thrombosis.

Door to balloon time is an important determinant of quality of care. Recommended time as per American College of Cardiology (ACC)/ American Heart Association (AHA) guidelines is 90 minutes.However achieving this time is possible only in ideal world scenario. In developing countries like Bangladesh, financial constraints and delay in decision making due to lack of knowledge on behalf of patients and their relatives regarding importance of time in management of critical illness like myocardial infarction, turned out to be the major obstacle in following door to balloon time recommendations. In our study the median door to balloon time was 110 minutes with $40 \%$ of patients having PCI performed at or more than 90 minutes due to above mentioned reasons. However if we look at recent study by Zhang conducted in China, the median door-toballoon time reported for primary PCI was 132 min and only $22 \%$ of patients had PCI performed in $\leq 90$ minutes ${ }^{17}$.

Our study has some limitations that deserve attention. This is our observational study performed in selected patient group. There was only three female patient in our study. So out come of primary PCI in female group could not be assessed properly. Lack of availability of IVUS was also a drawback for us to see intravascular thrombus burden and exact stent implantation.

In summary we found that primary PCI is safe and it increased the in-hospital and 30 days survival out come in patient with acute myocardial infarction. We conclude that with increasing awareness and the wider availability of primary PCI, this procedure will be performed more frequently and thrombolytic therapy will no more be the first choice therapy for treatment of STEMI in our set up.

\section{References:}

1. De Luca G, Suryapranata H, Marino P. Reperfusion strategies in acute ST-elevation myocardial infarction: an overview of current status. Prog Cardiovase Dis 2008; 50:352-82.

2. Cannon CP, Evolving management of ST-segment myocardial infarction; update on recent data Am J Cardiol 2006, 98:10Q21Q.

3. Reddy NR, aju PR, Kapoor S, Rao MS, Reddy RP, Sastry BK et al. Prospective observational study of primary angioplasty of the infarct-related artery for acute myocardial infarction. Indian Heart J 1999; 51:167-72.

4. AGM Reza, AHMW Islam, S Munwar , S Talukder. Study on primary percutaneous coronary intervention (PCI) in patient with Acute Myocardial Infarction : In hospital; and 30 days survival out come: Cardiovascular J 2010; 2: 212-217.

5. ISIS-2 (Second International Study of Infarct Survival) Collaborative Group Randomized trial of intravenous streptokinase oral aspirin, both, or neither among 17,187 cases of suspected acute myocardial infarction ISIS-2. Lancet 1988; 2: 349-60.

6. Effectiveness of intravenous thrombolytic treatment in acute myocardial infarction. Gruppo Italiano per lo studio della Streptokinase nell Infarto Miocardico GISSI) Lancet 1986; 1:397-403.

7. Ball GS Thrombolysis too old and too young. Heart 2002; 87:312-3.

8. Keeley EC, Boura JA, Grines CL. Primary angioplasty versus intravenous thrombolytic therapy for acute myocardial infarction: a quantitative revew of 23 randomized trials. Lancet 2003; 361:13-20.

9. Widimsky P, Bilkova D, Penicka M, Novak M, Lanikova M, Porizka V et al. Long-term outcomes of patients with acute myocardial infarction presenting in hospital without catheterization laboratory and randomized to immediate thrombolysis or interhospital transport for primary percutaneous coronary intervention. Five years follow-up of the PRAGUE-2 trial Eur Heart J 2007; 28: 679-84.

10. Aversano T, Aversano LT, Passamani F, Kratterud GE, Terra MI, WilliamDO. Thrombolytic therapy vs primary percutaneous coronary intervention for myocardial infarction I n patients presenting to hospital without on-site cardiac surgery: a randomized controlled trial. JAMA 2002; 287: 1943-51.

11. de Boer MJ van Hout BA, Liem AL, Suryaprata H, Hoonitje JC, Zijlstra F. A cost-effective analysis of primary coronary angioplasty versus thrombolysis for acute myocardial infarction. Am J Cardiol 1995; 76: 830-3.

12. Tiefenbrum AJ, handra NC, French WJ, Gore JM, Rogers WJ. Clinical experience with primary percutaneous transluminal coronary angioplasty compared with alteplase (recombinant tissue-type plasminogen activatory) in patients with acute myocardial infarction: a report from the Second National Registry of Myocardial Infarction (NRMI-2). J Am oll Cardiol 1998; 31: 1240-5.

13. Primary Versus tettecteplase-facilitated percutaneous coronary intervention in patients with ST-segment elevation acute myocardial infarction (ASSENT-4 PCI): randomized trial. Lancet 2006; 367: 569-78.

14. Webb JG, Sanborn TA, Sleeper LA, Carere RG, Buller CE, Slater JN et al. Percutaneous coronary intervention for cardiogenic shock in the SHOCK Trial Registry. Am Heart J 2001; 141: 964-70.

15. Klein LW, Shaw RE, Krone RJ, Brindis RG, Anderson HV, Block PC et al. Mortality after emergent percutaneous coronary intervention in cardiogenic shock secondary to acute myocardial infarction and usefulness of a mortality prediction model. Am J Cardiol 2005; 96:35-41.

16. Hussain A, Siddique MS, Hanif B, Malik F, Hasan K, Fatima Adhi et al. Out comes of primary percutaneous intervention (PCI) in a Tertiary Care Cardiac Centre. JPMA 2009; 59: 426-429.

17. Zhang SY, Hu Dy, Sun YH, Yang JG. Current management of patients with ST elevation myocardial infarction in Metropoliton Beijing. China Clin Invest Ned 2008; 31: 189-97. 